\title{
Grid-based multi-energy systems-modelling, assessment, open source modelling frameworks and challenges
}

\author{
Lukas Kriechbaum* (1D), Gerhild Scheiber and Thomas Kienberger
}

\begin{abstract}
Background: The transition to a sustainable future challenges the current energy grids with the integration of variable, distributed renewable energy sources. On a technical level, multi-energy systems may provide the necessary flexibility to minimise the gap between demand and supply. Suitable methods and tools are necessary to derive relevant results and to support a transition to renewable energy sources. While several, dedicated tools to model grids and infrastructure of single-energy carriers exist, there are no tools capable of modelling multi-energy systems in detail. Thus, this paper presents the necessary aspects to consider when modelling grid-based multi-energy systems, presents three open source frameworks for modelling grid-based energy systems and points out the major challenges. Methodology: The current main aspects and challenges for modelling grid-based energy systems are derived from a literature review. Three open source multi-energy modelling frameworks (Calliope, oemof, urbs) are presented, and the extent to which they consider these aspects and how they tackle challenges is analysed.

Grid-based MES modelling: We identified five general energy system modelling aspects (modelling scope, model formulation, spatial coverage, time horizon, data) and three aspects specific to modelling energy grids (level of detail, spatial resolution, temporal resolution). While the specific aspects mainly influence the representation of the technical parts of the energy system and the computational effort, the general aspects primarily relate to the system boundaries and scope of the model. For the evaluation of the modelling results, we identified several assessment criteria, including economic, energetic, exergetic and reliability. Each of the studied open source modelling frameworks provides generic capabilities to model energy converters, and the electricity, gas and district heat networks. However, the general and specific aspects present respective challenges. Relating to the general aspects, complexity of model formulation increases when including additional boundary conditions. The accuracy of the results is also dependent on data quality. Temporal and spatial resolutions are the major specific challenges for modelling the energy infrastructure. Conclusions: There is still a broad field of opportunities for researchers to contribute to grid-based energy system modelling. This encompasses especially the consideration of short- and long-term dynamics of renewable energy sources in planning models.
\end{abstract}

Keywords: Energy systems analysis, Energy assessment, Open source energy modelling frameworks

\section{Background}

Clean and sustainable energy supply is a societal challenge of the twenty-first century. Despite the world's primary energy supply rising from 255 to 571 EJ between 1973 and 2015, the share of energy produced from fossil fuels has not changed significantly and is currently still

*Correspondence: lukas.kriechbaum@unileoben.ac.at

Chair of Energy Network Technology, Montanuniversitaet Leoben,

Franz-Josef-Strasse 18, 8700, Leoben, Austria above $80 \%$ [1]. Different studies project a primary energy consumption between 770 and $1175 \mathrm{EJ}$ in 2050 due to population and economic growth [2]. Over the upcoming decades, the primary energy supply from fossil fuels is expected to rise by approximately $1.5 \%$ per year [3]. Until now, the utilisation of fossil fuels accounts for $68 \%$ of the world's anthropogenic greenhouse gas emissions [4]. In order to mitigate global warming, mainly caused by anthropogenic green house gas emissions, the parties of the United Nations Framework Convention on Climate 
Change reached an agreement on lowering carbon energy supply at the COP 21 in Paris [5]. The participating countries must adapt their energy policies to achieve the goals of the Paris agreement. Energy policy as a distinct field emerged with the occurrence of the first oil crisis [6]. Energy system models provide 'the integrating framework that assists energy policy and industrial decision makers' [7]. The main goal of energy system modelling was 'not to compute precise numbers but to gain insight into any complex system' [8]. Mathematical methods like linear programming developed for operations research in the Second World War $[9,10]$ were used to create models which allowed the formalisation of scattered knowledge about complex interactions in the energy sector and helped analysts to understand a sector that had become complex [11].

The history of energy system planning was primarily closed and proprietary, but market liberalisation and the need for greenhouse gas emissions reductions require changes in the transparency of modelling assumptions and methodologies [12]. Pfenninger et al. [12] present four reasons why data and models are not open: very often, sensitive data is used; sharing details and models creates an unwanted exposure, the effort to publish and maintain the model and institutional and personal inertia. However, transparency of the model, the datasets used and the communication of the assumptions made are all important points for the reproducibility and the acceptance of the results $[13,14]$.

The need for transparency and the challenge to integrate variable renewable energy sources (RES) [1] call for new types of models. These models must incorporate the rapid deployment and variability of wind and photovoltaic power loads as well as the growing importance of flexibility options like energy storage and grid expansion [15]. They must also consider high spatial, temporal and technological details to accurately assess and estimate the effects caused by such changes [12].

In this review article, we present a comprehensive overview of the current, grid-based multi-energy system (MES) modelling. The "Motivation" section is followed by the "Definitions and methodology" section-where we provide necessary descriptions of the review and derive our review approach. In the "Integrated gridbased MES modelling" section, we first present general MES modelling aspects as well as the specific grid-based MES modelling aspects. The modelling approaches for energy networks, storage and converters are outlined in the "Grid-based MES modelling approaches" section. This section is followed by the presentation of three open source modelling frameworks in the "MES open source modelling frameworks" section. Subsequently, in the "MES modelling challenges" section, we discuss current and possible future issues of MES modelling. The "Conclusions" section summarises and closes this review.

\section{Motivation}

Integrated energy system models try to create a representation of the various interactions between environment, resources, technology and investment, and economy and society (Fig. 1). Development of the first energy system models started in the 1970s. The Energy Technology Systems Analysis Program (ETSAP) of the International Energy Agency (IEA) first produced the MARKAL (MARket ALlocation) [16] modelling platform. The International Institute for Applied Systems Analysis (IIASA) developed its Model for Energy Supply Strategy Alternatives and their General Environmental Impact (MESSAGE $[17,18])$. Both models were originally designed for bottom up optimisation of large-scale energy systems of countries or at an international level. Therefore, they require extreme simplifications such as country level aggregated values and seasonal or annual supply and demand balance [19]. Because all of the simplifications were accepted and well understood in energy systems consisting of base-load and fully dispatchable generators, such an energy-based perspective was sufficient for the desired purpose of such models. However, due to the temporal variability of RES, those tools may not fully capture the complexity of current and future energy systems. This leads to the necessity of a power-based perspective of future energy systems.

In this review, we focus on integrated, grid-based MES for three main reasons: (1) for a decarbonisation of the global energy system, fossil fuels must be substituted by renewable electricity [20], (2) the integration of fluctuating RES is especially a challenge for the electricity grid [21] and (3) an integrated MES approach supports a better utilisation of volatile RES and existing grid infrastructures [22].

The first two reasons address the implications of substituting fossil fuels for RES. For example, the shift from gasoline or diesel cars to electric cars powered by renewable energy [23]. Reason (3) considers the need to provide flexibility and virtual storage capacities ${ }^{1}$ when integrating variable RES. This is to overcome the gap between fluctuating supply and demand.

As described in the introduction, most of the energy system models and modelling frameworks are opaque black or grey boxes. However, this has changed in recent years with the public release of many models and modelling frameworks [25]. Compared to proprietary models and modelling frameworks, in open source energy modelling, all stages of the process should be open and transparent (Fig. 2). According to [12], the main advantages of open source energy system models are (1) an improved quality of science due to increased transparency and reproducibility, (2) more effective and broader collaboration, (3) 


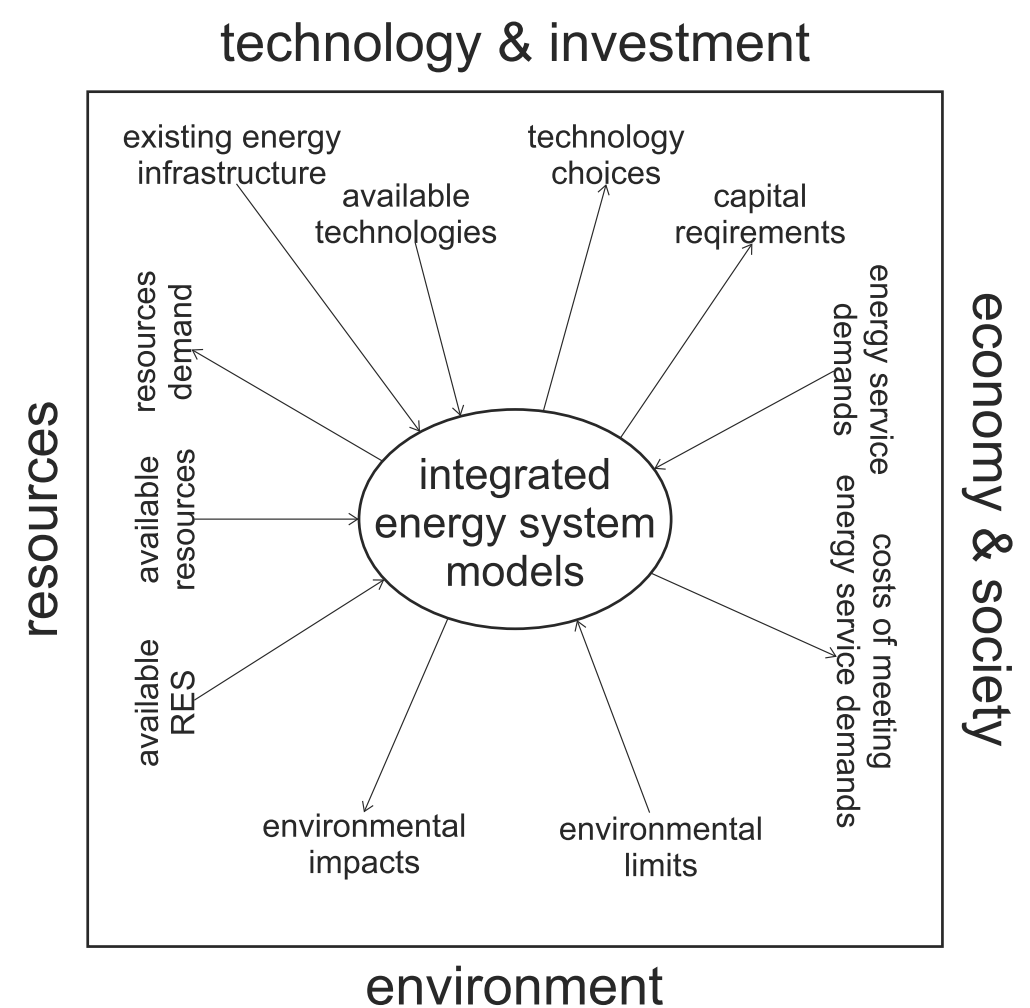

Fig. 1 Integrated energy systems modelling. Representation of the interactions between environment, resources, technology and investment, and economy and society in an integrated grid-based MES model. Adapted from [19]

increased productivity because of burden sharing and (4) a profound relevance to social debates.

\section{Definitions and methodology}

Different interpretations regarding the terminology and system boundaries in energy system modelling are available. Their use and interpretation within this paper is described in this section, together with the methodology of this review article.

\section{Definitions}

The system boundaries must be carefully selected in order to adequately assess the overall system. For MES, all energy carriers ranging from extraction to services must be included within the system boundaries. In this work, the definitions of an energy system and sector according to [27] are used. An energy system includes 'all steps in the chain-from primary energy resources to energy services'. The energy sector refers to 'the steps in the chain, from the extraction of primary energy resources to the delivery of final energy carriers for use in end-use technologies that produce energy services or goods'.

A consistent definition of Multi-Energy-Systems (MES) has currently not been found. In general, a MES approach requires holistic consideration of an energy system, covering the energy stages from the extraction and treatment (e.g. gas well, coal mine, sun) to the services (e.g. heating, illumination, transport), while also considering the different carriers (e.g. electricity, natural gas, oil, coal). In this paper, we focus on the grid-based energy carriers of the

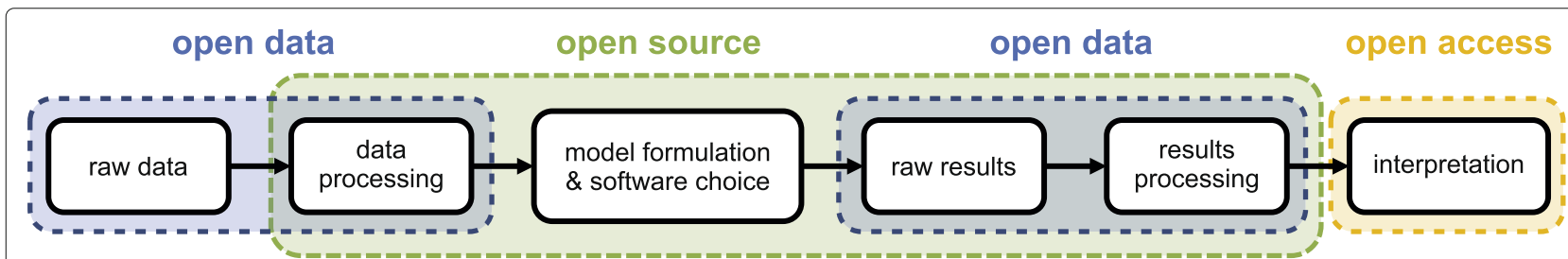

Fig. 2 Open source energy sytems modelling. Open access in all stages of the energey systems modelling process: open data, open source and open results. Taken from [26] 
energy sector in the range from primary energy to final energy (marked by the dashed box in Fig. 3). Mancarella [28] points out four categories to characterise MES: spatial, multi-service, multi-fuel and network. While multiservice means that one energy source can supply energy services at the same time (e.g. a combined heat and power plant), multi-fuel means that different services can be provided by multiple primary energy carriers (e.g. domestic heat can be produced by a heat pump or a gas boiler). The spatial category describes the spatial resolution of a MES model, where common resolutions are buildings, cities and entire countries. Energy networks are required to overcome the spatial distance between consumers and producers and to enable the development of multi-energy technologies and their interactions. In addition to the four categories Mancarella consider, time resolution should also be considered in models integrating variable RES and energy storage. Therefore, when considering MES in our work, five categories are incorporated: spatial, time, network, multi-service and the multi-fuel.

The definitions of model, model generator and framework are taken from [29]. Models are simplified replicas of real world systems and may consist of several hard- or soft-linked sub-models. Model generators allow users to build models by the use of pre-defined units (e.g. a pre-defined set of equations represents a storage unit and converter). A modelling framework is a structured toolbox and may consist of sub-frameworks and model generators.

\section{Methodology}

The aim of this review is to give a comprehensive overview and to discuss the requirements of grid-based MES models. Additionally, selected open source modelling frameworks are presented and characterised. Our work draws on several recent reviews of MES modelling and the implied challenges (Table 1). Additional literature was consulted where necessary. The reviews can be grouped into five different fields: general MES modelling $[19,28,30]$, modelling of urban MES [31, 32], categorisation of energy system models and frameworks [29, 33], evaluation of the challenges in energy system modelling [11] and the power flow modelling [34].

The review of Hall et al. [33] presents the prevalent usage and categorisation of energy system models in the UK. A qualitative evaluation method to categorise energy sytem modelling frameworks is proposed by Wiese et al.

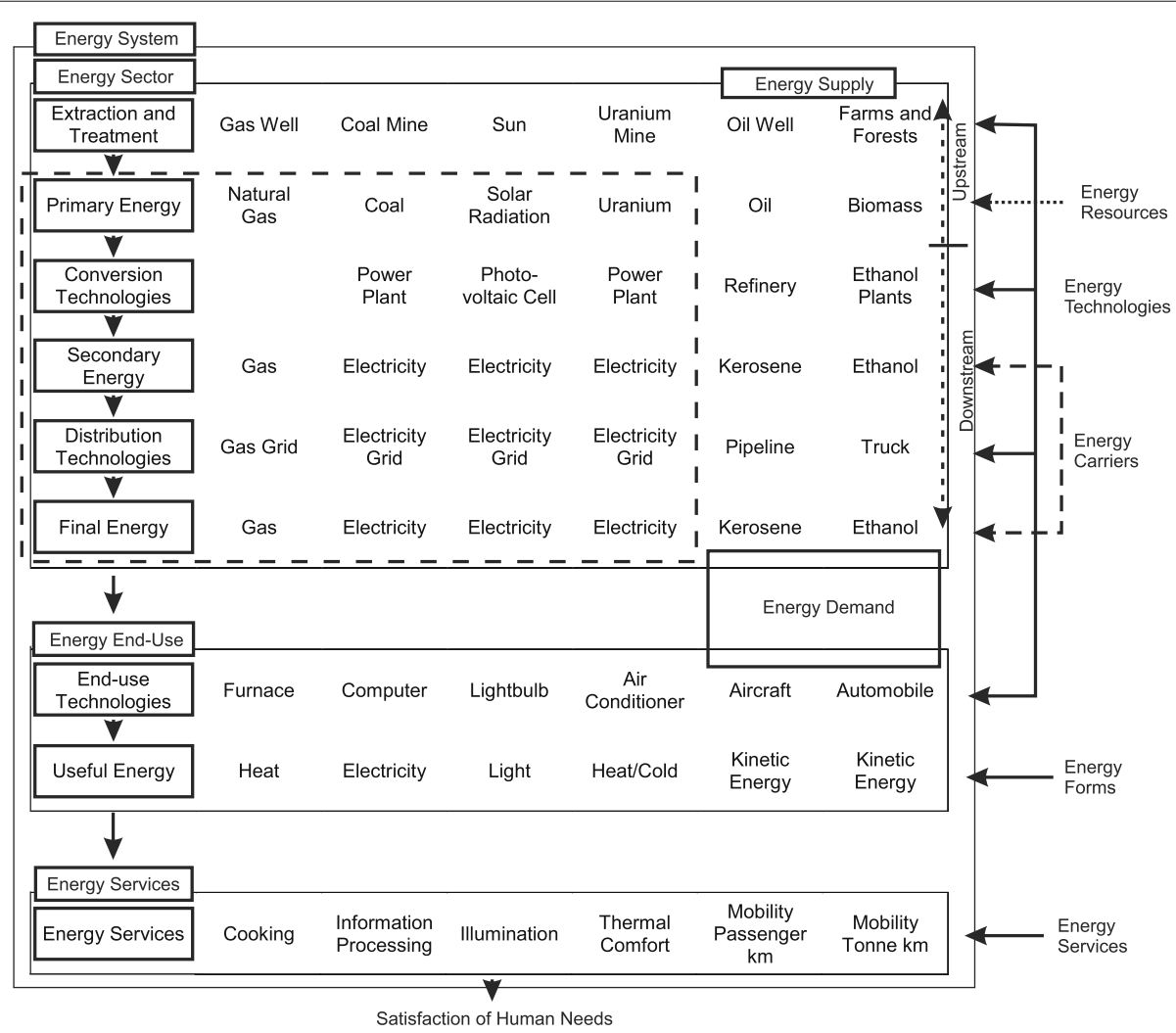

Fig. 3 Schematic of the energy system, energy sector, energy end-use and energy services. The energy sector includes the stages energy extraction and treatment, conversion, and distribution of final energy. The flow of the different energy carriers through the stages are illustrative examples and are not fixed. The system boundaries for this review are enclosed by the dashed box. Figure adapted from [27] 
Table 1 Relevant literature on MES modelling and modelling challenges

\begin{tabular}{|c|c|c|}
\hline Publication & Focus & Coverage \\
\hline Keirstead et al. [31] & $\begin{array}{l}\text { Urban energy } \\
\text { system models: } \\
\text { approaches and } \\
\text { challenges }\end{array}$ & 279 publications \\
\hline Mancarella [28] & $\begin{array}{l}\text { MES concepts } \\
\text { and modelling }\end{array}$ & 172 publications \\
\hline Pfenninger et al. [11] & $\begin{array}{l}\text { Challenges of } \\
\text { energy systems } \\
\text { modelling }\end{array}$ & 130 publications \\
\hline van Beuzekom et al. [32] & $\begin{array}{l}\text { MES for urban } \\
\text { sustainable } \\
\text { development }\end{array}$ & 78 publications \\
\hline Mancarella et al. [19] & $\begin{array}{l}\text { Integrated MES } \\
\text { modelling }\end{array}$ & 132 publications \\
\hline Hall et al. [33] & $\begin{array}{l}\text { Categorization of } \\
\text { energy system } \\
\text { models }\end{array}$ & 163 publications \\
\hline Syranidis et al. [34] & $\begin{array}{l}\text { Electric power } \\
\text { flow modelling }\end{array}$ & 138 publications \\
\hline Mohammadi et al. [30] & $\begin{array}{l}\text { Energy hub mod- } \\
\text { elling approach }\end{array}$ & 153 publications \\
\hline Wiese et al. [29] & $\begin{array}{l}\text { Evaluation of } \\
\text { energy } \\
\text { system modelling } \\
\text { frameworks }\end{array}$ & 91 publications \\
\hline
\end{tabular}

[29]. Mohammadi et al. [30] analyse recent developments in the field of the energy hub, which is a generic and extensive MES approach (further details can be found in the "Energy hub" section). In his review, Mancarella [28] gives a broad overview on the currently available MES concepts, evaluation models and assessment techniques. In a later review Mancarella et al. [19] focus on the modelling of integrated MES. They present the requirements, opportunities and MES modelling applications ranging from optimal unit scheduling, optimal RES integration and optimal power flow between energy hubs.

Van Beuzekom et al. [32] identify suitable modelling tools and frameworks, whereas Keirstead et al. [31] identify and evaluate the influence of technology design, building design, urban climate, systems design, policy assessment, and land use and transportation modelling. A further two reviews $[11,29]$ look at the general challenges of recent energy system modelling. Only one review was found which focuses on modelling of control techniques and the modelling of electrical power flow across transmission networks [34], but nothing was found regarding the modelling of natural gas or district heating grids.

We used the literature review to determine the general aspects, modelling approaches and challenges for modelling MES as well as those specific to grid-based energy systems. For the evaluation of such energy systems, suitable assessment criteria are provided. Three selected open source MES modelling frameworks are assessed. Specifically, the review analyses each framework's modelling approach and the extent to which the necessary aspects are considered.

We identified five general aspects important to MES modelling as well as three grid-specific aspects (Table 2). In the following section, each of the aspects is presented in further detail and discussed. The two most common modelling scopes today are planning and operation. While planning models evaluate the long-term evolution of the energy system, operational models assess the operational soundness of scenarios. For planning models, the time horizon is especially important because it determines how far the model looks into the future. MES may range from a single building to districts, cities or whole countries. This is described in the spatial coverage. The mathematical model formulation, together with the programming technique, influences the possible level of detail and the necessary computational effort. For detailed models, data availability is essential, since it is often not known or is of bad quality. The level of detail describes how thoroughly the physical properties of the single components (e.g. part load efficiencies, power flow models) are considered within the model. The necessary aggregation and network representation are mainly affected by the spatial resolution. For the integration of variable RES, the temporal resolution is important and determines to which extent short- and long-term dynamics can be considered.

The MES modelling approaches consist of full and hybrid concepts. While the full approaches consider all available energy carriers, the hybrid approaches consider only some. The different energy and power flow representations in electricity, gas and district heat networks provide various degrees of detail. They range from simple network flow models to more detailed power flow representations like DC or AC load flow.

Based on the general and specific modelling aspects, three open source modelling frameworks which are suited to model grid-based MES are evaluated according to the modelling aspects and approaches stated out above. The major requirements for such tools are the possibility to model multiple energy carriers, a temporal resolution to

Table 2 General and specific grid-based MES modelling aspects

\begin{tabular}{ll}
\hline General aspects & Specific aspects \\
\hline Modelling scope & Level of detail \\
Model formulation & Spatial resolution \\
Spatial coverage & Temporal resolution \\
Time horizon & \\
Data &
\end{tabular}


model the short and long term dynamics of RES, a spatial resolution to model energy or power flows and suitable network or power flow representations.

Also compiled from the literature review are the modelling challenges. Data availability, data quality and increased model complexity (e.g. because of modelling data uncertainty or human behaviour) are all challenges affecting the general modelling aspects. The specific challenges refer to the representation of time and space in the model.

\section{MES modelling aspects and assessment}

According to Box and Draper, 'essentially, all models are wrong but some are useful' [35]. To receive a useful result from a model, it is crucial to model the values which are relevant to the problem and not those which lend themselves to modelling [11]. Therefore, in the next sections, we discuss several important aspects for MES modelling, from general to specific grid-based modelling aspects to the assessment of the results.

\section{General aspects}

Top-down (or macroeconomic) and bottom-up (technoeconomic) are the currently most typical energy system modelling approaches (Table 3). Models using top-down approaches try to provide a holistic perspective of the economy (this includes economic growth, employment, trade, etc.), but only consider the energy sector in a simplified and aggregated manner. In comparison, bottom-up models incorporate more technological detail and use an economically driven approach for evaluating investigated technologies. This allows them to provide more detailed outlooks on future supply and demand and possible technology utilisation. The high technological detail requires extensive data. Many assumptions have to be made regarding technology diffusion, investments and operating cost [36].

Since modelling grid-based energy systems requires a high level of technological detail we further focus only on bottom up modelling approaches in this work.

\section{Modelling scope}

Planning models are used to investigate the long term evolution of energy systems. They consider investment

Table 3 Energy systems modelling approaches [36]

\begin{tabular}{ll}
\hline Top-down & Bottom-up \\
\hline Input-output models & Simulation models \\
Econometric models & Optimisation models \\
Computable general equilibrium models & Partial equilibrium models \\
System dynamics models & Multi-agent models \\
\hline
\end{tabular}

decisions and account for a change in future parameters like fossil fuel availability, renewable resources, technology prices, technology diffusion and future learning. These parameters are input variables for energy systems models, and must be chosen carefully to avoid creating biased results [29]. Typical energy planning models are MARKAL/TIMES and MESSAGE. Planning models typically use an energy-based perspective because they work with highly aggregated data (e.g. annual demand and supply values). Operational models examine the operational feasibility of a scenario and since the energy demand must be met at any time of the investigated period, a powerbased perspective is necessary. This requires consideration of the short and long term dynamics of supply and demand, as well as technological, regulatory, economic and social constraints [15]. Typical operational models are PLEXOS, GTmax and EnergyPLAN.

\section{Time horizon}

The time horizon is closely connected to the modelling scope. While common time horizons for planning model are 30 to 50 years, typical investigation periods for operational models range from a day to a year [32, 37].

\section{Spatial coverage}

The spatial coverage may range from a local, single building to districts and countries. It has a vast impact on the suitable programming techniques, the possible level of detail [38], and the possible time horizons and time-steps [37]. A classification of current MES models according to their spatial dimension and level of detail shows that models which cover a spatial dimension that is greater than multiple buildings usually use rather simple, highly aggregated modelling approaches with constant conversion efficiencies between energy carriers (Fig. 4, see also sections "Programming techniques" and 'Level of detail') [38].

\section{Model formulation}

The most common modelling approaches for bottomup models are simulation ${ }^{2}$, optimisation ${ }^{3}$ and partialequilibrium ${ }^{4}$ models [36]. Newer approaches include agent-based-modelling and co-simulation [39]. While simulation is descriptive, meaning it forecasts how the energy system might evolve, optimisation is normativeits primary aim being to provide scenarios of how the energy system could evolve [11].

Describing the physical world (e.g. energy generation, distribution, infrastructure and their components) usually results in continuous models with linear and non-linear behaviour [40]. To create mathematically tractable models for integrated simulation or optimisation problems, the equations must be brought to a common problem formulation. The ones most commonly used are linear 


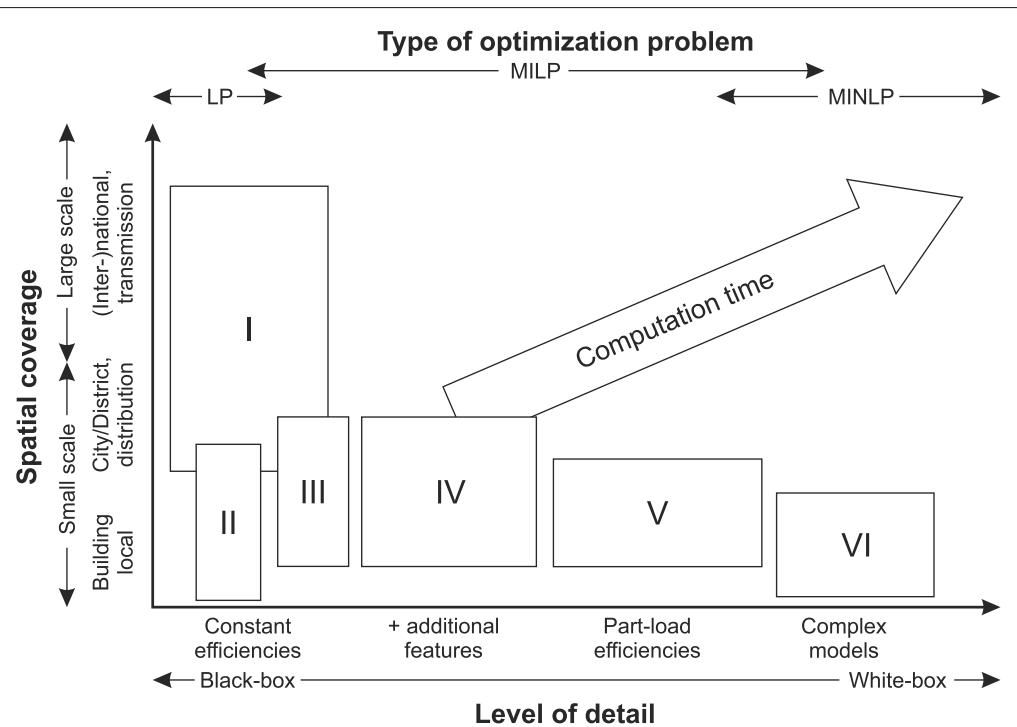

Fig. 4 Spatial coverage, model level of detail and typical optimisation problem formulation. Classification of existing MES models according to their level of detail and spatial resolution. I: large-scale grid studies relying on simplified models, II: simple tools for quick assessments of small-scale energy systems, III: building and city district energy system design studies with simplified models, IV: on-site energy system studies with additional features, V: mixed-integer linear programming with part-load efficiencies and VI: mixed-integer non-linear programming with complex models. Adapted from [38]

programming (LP), mixed-integer linear programming (MILP), mixed integer non-linear programming (MINLP) and dynamic programming (DP) [13]. In LP, all relationships are expressed in fully linearised terms that makes it an eas-to-use technique which delivers quick results [41]. However, the constant coefficients are also one of its main disadvantages, leading to deviations if describing non-linear phenomena. Almost all optimisation models for energy planning and technology-related, long-term energy research are LP models [37]. MILP is an extension of LP as it allows a greater detail in formulating technical properties and relations. It adds decision variables and non-convex relations which allow, for example, to model an on/off mode for individual units [42]. MINLP can also take into account non-linear objective functions and constraints meaning that it most closely approximates real world systems [43]. However, this adds a layer of complexity since the identification of the global optimum among the local optima in non-linear problems requires greater computational effort [44]. Because of the computationally costly solution process, MILP and MINLP models are usually applied only on small scale energy systems (Fig. 4, e.g. for dispatch modelling of combined heat and power plants [42] or thermal energy storage utilisation in an energy system with high shares of distributed energy sources [45]). DP is a method to find the optimum growth path. The problem is divided into several simple sub-problems for which the optimum solution is calculated and then combined to a global solution [41]. This method was applied for example on distribution system expansion planning
[46] or the optimal operation of a distribution network with dispersed generation units [47].

\section{Data}

The vast amount of data required for detailed bottom-up models causes challenges for the modellers. The necessary data is often not available because it is either not measured (high resolution load profiles of gas and electricity), is commercially confidential [48], relates to the future and is highly uncertain [19], or is of doubtful quality. Even though several methods exist to deal with this issue (probabilistic approaches, possibilistic approaches, interval programming, robust optimisation, etc. [49]), the majority of energy system models uses a deterministic logic (e.g. MARKAL, MESSAGE, etc.) and do not take into account any uncertainties. Probabilistic approaches use probability density functions for the input variables [9], for example the Weibull distribution of wind speed patterns [50]. In comparison, possibilistic approaches, also called fuzzy approaches, use membership functions to describe uncertainties [51]. Interval linear programming can deal with uncertainties in the system constraints and the objective function, as the lower and upper boundaries are specified. However, it cannot handle distribution functions [52].

\section{Specific modelling aspects}

While planning models have a long time horizon and coarse temporal and spatial resolutions, operational models have a significantly shorter time horizon and finer 
temporal and spatial resolutions. The variable and distributed nature of RES, the inclusion of energy storage, and the restricted transport capacities of transmission lines demands that finer temporal and spatial resolutions be used [11]. This calls for an increased level of detail which has an influence on the mathematical tractability and computational effort (Fig. 4). The different energy vectors and the technical infrastructure in a MES may require particular levels of detail, temporal and spatial resolutions [19]. These topics have recently been subject to many reviews, [53-57] evaluated the different levels of technical detail, $[15,53,54,58-61]$ focus on the temporal resolution and $[62,63]$ on the spatial details.

\section{Level of detail}

The different levels of detail can be divided into three categories: black-box, grey-box and white-box representations [64]. Black-box models are highly aggregated, databased input-output models without a representation of the underlying physical principles [65]. Therefore, they lead to straightforward and easy-to-solve models. However, it should be ensured that they are appropriate and accurate enough for the relevant problem [66]. Whitebox models offer higher degrees of detail and are based on physical principles to calculate load flows and conversion efficiencies [65]. This also leads to increased modelling effort and the mathematical tractability of the model may cause issues [66]. Grey-box models use simplified physical representations, and their aggregation level and degree of detail is in between that of a white-box model and a black-box model [67] Almost all tools used for nationwide energy forecasts (e.g MARKAL/TIMES, MESSAGE, etc.) use grey-box or black-box approaches. As shown in Fig. 4, complex white box models have limited spatial coverage, there is no known model which features both.

\section{Spatial resolution}

MES models should consider spatial dimensions because energy supply and demand often occur in different locations. To connect demand with supply, energy transfer infrastructure is necessary [19]. The smallest known common entities in MES modelling are houses and residential buildings. In several papers, MES houses were addressed. Some examples include the high resolution modelling of residential demand [68] or the optimum integration of MES devices into buildings at design stage [69]. MES of the next resolution size-district or city-are the subject of intense research and many publications. In [70], integrated green- and brownfield MES approaches are used to determine the optimum solution for a district's future energy system. Another publication [22] deals with the exergetic optimisation of a city's grid-based energy system. Studies with a higher spatial coverage (e.g. $[71,72])$ usually do not account for system operation and infrastructure details [19].

Aggregation of data is crucial for modelling MES. On the one hand, to make the problem computationally tractable and, on the other hand, to account for unavailable or unmeasured data, different spatial and temporal resolutions may lead to deviating results. For district heating in the UK, [73] used a spatially explicit model to model future district heat scenarios and [74] determined that different spatial resolutions provide different results for the optimum heat supply strategies. For electrical networks, bus-aggregation methods are used for network reductions $[75,76]$. Such simplified networks are further used to determine the effects of aggregating electric loads in the USA [77] and Europe [76].

\section{Temporal resolution}

Using time-aggregated data, for example averaged hourly values, can lead to deviations in the results. For example, [78] showed that the design capacity of a micro combined heat and power plant varied by half between analysis using 5-min and 1-h time-steps. The necessary temporal and spatial scales for grid planning and operation as well as the resolutions of current MES tools are shown in Fig. 5. When modelling, it is assumed that fast phenomena have reached equilibrium at the end of a time-step. This is especially challenging when modelling MES as they cover a wide range of time scales, including microseconds in electric system operations, hours for gas transport in transmission lines and months in the case of seasonal influences of RES [19]. A possible solution to this problem is to interlink long-term energy system models with short term electricity system models. However, while the information flow from long-term models to short-term models works quite well, the reverse seems to be more challenging [55]. A major challenge in MES modelling is to select a proper temporal resolution to fit the scope. The shares of RES which can be integrated might be over- or under-estimated if an unsuitable resolution is chosen [15], for example [32] suggests a 15-min interval.

\section{Assessment criteria}

Choosing the appropriate assessment criterion and performance indicators is critical in the evaluation of MES. The most common criteria are economic, environmental or technical (energetic or exergetic). Qualitative and quantitative criteria exist, but only quantitative criteria can be used for the formulation of objective functions. The assessment and performance indicators can derive from an absolute or relative value, and a single- or multiobjective approach [28]. Other criteria like sustainability, resilience or socio-ecological effects are not considered in this section. 


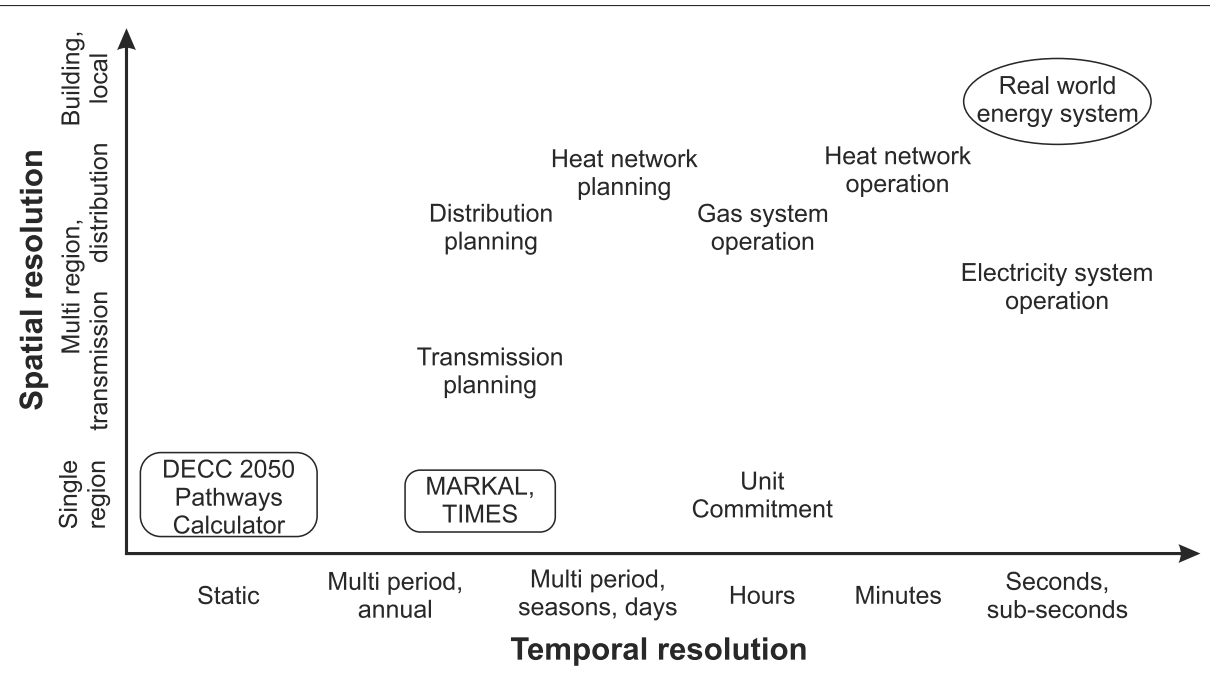

Fig. 5 Spatial and temporal scales in MES. The different spatial and temporal scales required for MES planning and operation and current MES model resolutions. Adapted from [19]

An Economic Assessment is the most widely used evaluation criterion. It can be applied anywhere from planning to the operational stage. The main premise is the minimisation of the total cost or the maximisation of profits. For planning purposes, the discounted cash flow or the net present value theory are usually used. At the operational stage, the analysis of costs and revenues caused by system operation is the typical approach.

An Energetic Assessment is the comparison of energy output to energy input, also called first law efficiency or energy efficiency. This can be conducted for individual components or whole systems during a particular operating state or over a certain period of time. Energy efficiency must always be compared to a reference case. An example of a relative indicator is when comparing energy savings by cogeneration to separate production [79].

An Exergetic Assessment considers the first and the second law of thermodynamics. Exergy describes the maximum share of energy that can be converted to useful technical work. While energy can be neither produced nor destroyed, it is the exergy that is consumed to provide a certain service. Therefore, exergy is a suitable common basis when comparing different energy carriers in a MES. Exergy analysis allows the evaluation of cascading energy usage and is a powerful tool for identifying causes, locations and magnitudes of primary energy losses [80].

An Environmental Assessment is an important criterion in the field of energy policy development. It covers the wide range of impacts of MES on the environment, like greenhouse gas emissions, air pollutants, influence on biodiversity and groundwater resources. In general it can be distinguished between local impacts, for example particulate matter and $\mathrm{NO}_{\mathrm{x}}$-emissions, and global impacts, such as greenhouse gases and chlorofluorocarbons. In this work, the environmental assessment focuses on the $\mathrm{CO}_{2}$-emissions related to energy production.

The Reliability Assessment rates the ability of energy systems to provide an adequate supply. The main aim of the reliability assessment is to identify the weak and critical parts of the energy infrastructure, such as the outage rates of generating units, the failure rates of overhead lines and operational decisions. All those are predicted future events which cannot be estimated precisely and therefore have to be assessed probabilistically. Typical key performance indicators are loss of load probability (LOLP), loss of load expectation (LOLE), expected energy not served (EENS) and loss of energy expectation (LOEE) [81].

\section{Grid-based MES modelling approaches}

In addition to supply and demand, grid-based MES models must consider the energy flows in the networks, energy storage and the energy conversion between networks. Two approaches are used to model such systems: the integrated approach and model linkage or co-simulation. In the integrated approach, all components (networks, converters, storage) are modelled within the same framework. Co-simulation or model linkage means that several or all components have their own dedicated model, which are coupled by a superior tool. For the coupling tool, the sub-systems are black boxes.

\section{Energy network modelling approaches}

Energy transmission via networks can be modelled in various levels of detail. Geidl [82] suggests a classification into network (black-box models) and power flow (grey- or white-box models) models. Type I network flow models feature energy flows that transmit energy without losses. Conversely, in type II network flow models, losses are 
incorporated as a function of the corresponding flow. Power flow models are the most accurate and based on conservation of flow and on conservation laws, but also include non-linearities.

While the network flow models are relatively simple and the same for each of the three most common energy networks (electricity, gas and district heat), the power flow models are more complicated. Physical laws such as the relation between electric voltage and current, or hydraulic pressure and flow, are used to determine the load flows. Since these physical relations are specific for the individual energy carriers, no general model for all energy carriers is available [82]. For each network type there are dedicated static load flow calculation tools which are based on physical laws, for example NEPLAN ${ }^{5}$, PSS SINCAL ${ }^{6}$ or DIgSILENT PowerFactory ${ }^{7}$. As well as modelling electricity networks, the first two tools can also model district heat and gas networks, however, it is not possible to interconnect each energy carrier.

\section{Electric networks}

There are two different approaches to model electrical power flow, the linear DC model and the more realistic AC model [83]. For the DC model, Kirchhoff's law is used to determine the active power flows which depend on the maximum power capacity and the resistance of the power lines [84]. Very often, linear DC power flow is used in operational electricity system models to decrease the complexity and calculation time for the non-linear optimal power flow problem [85]. For example, DC load flow models were used in two recent studies on the German electricity grid. One [86] investigated the necessary long term grid expansion due to the RES integration, the other was used to determine the optimal placing of storage power plants in 2020 [87]. DC load flow network representation was also used for an integrated day-ahead electricity market model in Turkey [88]. Several papers address the accuracy of DC load flow formulations [89] or compare results gained by $\mathrm{AC}$ and $\mathrm{DC}$ formulations $[85,90,91]$.

As AC load flow representations also account for active and reactive power flows, data regarding capacitive and inductive behaviour of the transmission lines is required. However, this increased detail adds to the complexity of the model and results in longer calculation times [84]. Solving large-scale electricity systems with an AC power flow representation is still a challenge because for some operation states, standard methods like Newton-Raphson or optimal power flow do not deliver any results [85] and prevent full $\mathrm{AC}$ power flow models from being widely adopted in real time operation [92]. All of the above mentioned load flow calculation tools are capable of AC power flow calculations. Geidl and Andersson [93] used an AC load flow representation to determine the optimum power flow in an interconnected system of energy hubs. Other applications are the determination of the optimal load flow in the distribution grid [94].

\section{Pipeline networks}

Power flow models for pipeline networks must consider pressure losses and, in the case of district heat grids, must also consider heat losses and the temperatures of the feed and return flows. The tools described above, NEPLAN and PSS SINCAL, can solve the non-linear power flow equations, for example by using the Newton-Raphson algorithm. The non-linear dependency between flow and pressure loss is a challenge in case of integrated MES simulation, because it requires either linearisation or a non-linear problem formulation. Several works have dealt with optimal power flow modelling in MES: for pipeline networks, they either linearised the equations [95] or used non-linear models [93, 96]. In practical modelling, generally static equations are used. This means that fast phenomena are negligible and have reached equilibrium before the end of the time-step [19]. In the case of fine time resolutions and large-scale pipeline networks, equilibrium might not be reached at the end of a time-step meaning full transient equations are necessary [97] to consider the changes in the linepack ${ }^{8}[19]$. The same applies if modelling storage that is intrinsically available in existing infrastructure, for example if using the slower dynamics as flexibility option for the power grid [99].

\section{Converter and storage modelling approaches}

There are several converter and storage modelling concepts with various levels of detail. The most generic one is the energy hub concept [100] which was specifically developed for describing the power flows in interconnected, grid-based MES. In his review, Mancarella [28] also includes the microgrid [101] and virtual power plant [102] modelling concepts, which were originally designed for power grid modelling, in the MES modelling concepts. A more recent concept is the power node modelling concept [103] - originally designed to model energy storage in electrical power systems. Whereas the energy hub is a full multi-energy modelling concept, the others primarily target the electricity system and only consider some multi-energy aspects, but do offer a higher degree of detail.

\section{Energy hub}

The energy hub concept is a generic approach for steady state modelling and optimisation of future interconnected multi-energy networks [82, 93]. The energy hubs serve as interfaces between different energy infrastructures (e.g. connecting the natural gas network to the electricity and heat grid using a co-generation plant) and network participants (consumers, producers). The basic elements of an 
energy hub are converters, energy storage, and input and output connections (Fig. 6). A converter is described by the energy efficiency $\eta_{\alpha, \beta}$ between input of energy carrier $\alpha$ and output of energy carrier $\beta$ and can have multiple power inputs $P^{\text {in }}$ and outputs $P^{\text {out }}$. A hub can consist of a single device or a combination of multiple converters and has dedicated inputs and outputs. The general formulation of energy conversion for a multi-input and multi-output hub is analogous to a single converter and can be stated as followed [104]:

$$
\left(\begin{array}{c}
P_{\alpha}^{\text {out }} \\
P_{\beta}^{\text {out }} \\
\vdots \\
P_{\omega}^{\text {out }}
\end{array}\right)=\left(\begin{array}{cccc}
\eta_{\alpha, \alpha} & \eta_{\beta, \alpha} & \cdots & \eta_{\omega, \alpha} \\
\eta_{\alpha, \beta} & \eta_{\beta, \beta} & \cdots & \eta_{\omega, \beta} \\
\vdots & \vdots & \ddots & \vdots \\
\eta_{\alpha, \omega} & \eta_{\beta, \omega} & \cdots & \eta_{\omega, \omega}
\end{array}\right)\left(\begin{array}{c}
P_{\alpha}^{\text {in }} \\
P_{\beta}^{\text {in }} \\
\vdots \\
P_{\omega}^{\text {in }}
\end{array}\right)
$$

Energy systems of various scales and resolutions can be represented by a set of interconnected energy hubs. The energy transmission between the hubs can be represented by network or power flow models. The original approach uses a black-box modelling approach with constant conversion efficiencies for converters.

The majority of energy hub applications use an integrated modelling approach. Although the energy hub concept was originally developed for greenfield design studies [105], it has been used for several other purposes. In addition to optimal dispatch [104], optimal power flow modelling in the networks [93] and topological optimisation [106], energy hub models were also used for reliability considerations [107] and exergetic optimisation [108]. A decent collection of published research on the energy hub can be found in [30].

\section{Hybrid concepts}

A micro-grid is a distribution system with interconnected loads and distributed energy sources (PV, wind, storage, etc.) which is controlled in a coordinated way, allowing it to operate in parallel with the grid or in island mode [109]. Micro-grids can be MES, if the loads and supplies of other forms of energy are included in their control strategy as well. Examples are the integration of co- and tri-generation as well as electrical heat pumps. A tool for efficient design and operation of polygeneration micro-grids was presented by $[110,111]$. The application of a MES micro-grid was shown at the University of Genua [112].

A virtual power plant (VPP) is a flexible representation of a portfolio of distributed energy resources. They are aggregated and coordinated in a way so that they act as a single power plant [113]. Currently, small power generation facilities like battery storage and distributed energy resources are generally prohibited from the electricity spot market [114]. Virtual power plants can help overcome these barriers and meet the requirements for participation in the European Energy Exchange spot market [115] and the control energy tenders $[116,117]$. The application of VPP in MES concentrates on providing system flexibility, for example by including thermal storage in a cluster of CHP plants [118] or by using aggregated resources like heat pumps, electric vehicles and electrolysers in replace of the spinning reserve [119]. For example, a VPP model is used to evaluate the feasibility of balancing the power in a renewables only power system using CHP, heat pumps and thermal storage [120].

The Power Nodes modelling concept is based on a Multilevel Flow modelling approach, which is usually used to model industrial processes on several interconnected levels [121]. A power node represents a generic storage which is inserted in between the grid and the supply and demand processes. This adds a new degree of freedom to balance the power grid and works in tandem with controllable loads by offering inherent storage capacity.

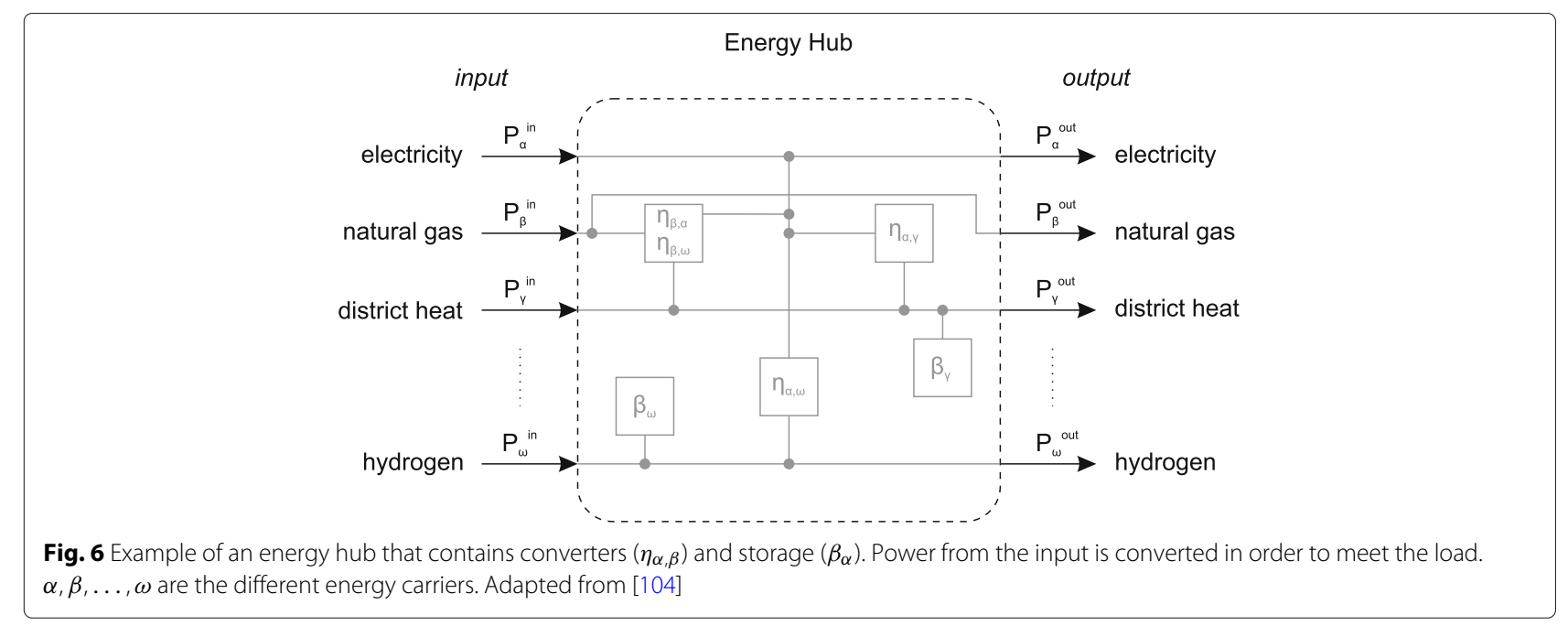


In order to provide a conceptual model for energy storage and different levels of controllability of power system units the power node approach aims to introduce a model decomposition for operation functions in different planning stages and operation time-scales' [122]. A multi-stage formulation is used to provide equations for day-ahead and intra-day rescheduling as well as real-time operation. Although the power node modelling concept is mainly designed solely for electricity grid simulations, it may also be used in a MES context when considering power-to-heat applications. In a case study, a power grid with intermittent electricity supply, thermal load and thermal energy storage was investigated [103, 122, 123].

\section{MES open source modelling frameworks}

While in earlier times, models designed for urban or utility energy systems were not commercially available [124], the situation has changed and today there are several accessible MES modelling concepts and open source modelling frameworks. For our review, a collection of 29 open source energy modelling tools was established from $[25,125,126]$. The complete collection, including information regarding the properties of the tools (e.g. programming language, available energy sectors, time resolution, energy grids), can be found in Additional file 1. Sixteen of these tools support modelling energy grids, and only seven of those allow the modelling of more than a single energy carrier. Balmorel [127], ficus [128] and PyPSA [129] focus on modelling electricity and heat supply. TransiEnt [130] is a Dymola library for modelling the transient behaviour of electricity, gas and district heat networks. Calliope [131], oemof [132] and urbs [133] are the most generic and flexible modelling frameworks as they support modelling user-defined energy sectors and grids. They also allow user-defined time-resolutions and horizons. Therefore we selected them for a further evaluation according to the modelling aspects and approaches stated above. A short description of each framework is provided followed by a comparison.

\section{Calliope}

Calliope is a framework used to model MES, developed by the universities ETH Zürich and University of Cambridge. The model is written in Python and has a clear separation of framework (code) and model (data). The focus is set on spatial and temporal explicitness, openness, transparency and the ability to compute and compare a large number of scenarios [11].

\section{oemof}

oemof is a 'modular open source framework to model energy supply systems' developed by the Reiner Lemoine Institut and the Center for Sustainable Energy Systems at Flensburg University of Applied Sciences. It is a collaborative modelling approach that is still under development. The modular structure offers the ability to adapt to the desired scope, making it flexible in time resolution and allows for the connection of multiple regions and energy sectors. It provides a rich set of tools to construct energy supply system models in high temporal and spatial resolution. The object-oriented implementation of the framework allows users to address the uncertainties of highly integrated future energy systems [134].

\section{urbs}

urbs is an energy modelling framework developed by the Technical University of Munich. It is a linear programming optimisation model built for capacity expansion planning and unit commitment for distributed energy systems. It is suitable for MES with a focus on optimising storage size and use. The optimisation objective is to minimise the cost of the energy system while satisfying the given demand [133].

\section{Framework comparison}

The general and specific characteristics of the modelling frameworks are summarised in Table 4. All of the modelling frameworks are based on the energy hub concept and cover the electricity, heat and gas sector. oemof stands out with the option to include the transport sector. The basic features included are renewable energy sources, converters (including co- and tri-generation), consumers, storage and grids for electricity, heat and gas. Type II network flow models are used to describe the energy transmission between multiple regions. Since all frameworks have operational and planning modes incorporated, they support high time resolutions and long term investigation periods. Using a deterministic optimisation model formulation, all frameworks accept linear equations. oemof and Calliope also accept binary variables. This only allows a basic level of detail but high spatial coverage.

The main objective of all frameworks is to minimise costs for a given scenario. As well as economic constraints, urbs also offers the opportunity to include $\mathrm{CO}_{2}$ emissions as an auxiliary constraint. The economic analysis of urbs is especially advanced as it includes a number of economic variables outside of the fixed and variable standard costs. It allows the user to explore investment costs, start-up cost, time variable buy and sell prices for commodities and an annuity factor formula for a given depreciation duration and interest rate. Even though the basic functions of the tools are quite similar, they also have some unique features. Calliope and urbs support multi-scenario evaluation and urbs also provides demand response, while oemof offers the implementation of minimum up- and down-times for converters.

The source codes for all the frameworks are hosted on github ${ }^{9}$. The number of commits ${ }^{10}$ made on these projects 
Table 4 General and specific characteristics and features of the modelling frameworks

\begin{tabular}{llll}
\hline & Calliope & oemof & urbs \\
\hline Modelling scope & Operational, planning & Operational, planning & Operational, planning \\
Model formulation & Linear & Linear and mixed integer & Linear \\
Spatial coverage & Local to countries & Local to countries & Local to countries \\
Time horizon & Short and long & Short and long & Short and long \\
Assessment criteria & Economic & Economic & Economic, with \\
& & & environmental \\
& & auxiliary \\
MES approach & Energy hub & Energy hub & Energy hub \\
Energy sectoral coverage & Electricity, gas, heat & Electricity, gas, heat, transport & Electricity, gas, heat \\
Spatial resolution & Single- and multi-region & Single- and multi-region & Single- and multi-region \\
Time resolution & Low and high & Low and high & Low and high \\
Load flows & Network flow type II & Network flow type II & Network flow type II \\
Unique features & Ramp rates, multi-scenario & Ramp rates for storage, up- and down times & Demand response, \\
& & & multi-scenario \\
\hline
\end{tabular}

indicates that all projects continue to have active online communities who are further developing the codes and correcting errors. Road maps and feature lists show the path and schedule for future developments and releases. Issues and bug reports posted on github are usually answered and fixed by the developer community within a reasonable time.

Appropriate documentations help to support new users with understanding the structure and functions of the frameworks. Compared to the other frameworks, urbs has broader ranging application possibilities which are supported by more extensively and detailed documentation. The well-structured source code of each framework is straightforward and of high quality. However, urbs stands out because its in-code documentation includes more details and additional information.

Even though urbs has the most extensive documentation, the broad functionality and sophisticated economic assessment make it time consuming to change the code. A considerable advantage of oemof is the clear and modular structure of the code which allows it to be easily adapted. In comparison to oemof, Calliope does not have such clear and strict separation between the model description, simulation and optimisation.

\section{MES modelling challenges}

Energy system modelling is influenced by various sectors and fields (see Fig. 1 and Table 5). As well as detailing energy infrastructure components and technology, energy system models must also account for the stochastic nature of RES and the behaviour of consumers and market stakeholders.

\section{General aspects}

The main challenge when modelling an energy system is to accurately model the desired problem, and to select the proper influencing factors and boundary conditions. It is important to model the factors that are relevant to the problem instead of prioritising factors that may be easier to use [11]. While energy system models are often implemented for technological and economic effects, they are rarely used to investigate the effects of aspects such as human behaviour, indirect costs, socio-political or nonfinancial barriers for technology [11].

Energy systems typically consist of the four interconnected fields listed in Table 5. On the path to a future energy system based on distributed RES, the number of interconnections between the individual energy carriers will need to increase. This adds to the complexity of the system and increases the overheads for maintenance $[135,136]$.

\section{Model formulation}

While there are several specialised and dedicated tools for modelling the individual segments of the energy system in various detail, there is no known transdisciplinary tool or method that combines all four fields stated in Table 5 in high detail. The more convoluted and interconnected a system becomes, the more difficult it is to solve the arising mathematical problem. Already when only modelling components and grids of a MES using the energy hub concept, the synthetic matrix representation leads to a model formulation that is intrinsically nonlinear due to the multiplication of decision variables [28]. Optimisation problems with non-linear constraints require additional optimality conditions (Karush-Kuhn-Tucker conditions) to find a globally optimal solution [82]. This makes the mathematical problem more difficult to solve. Another approach is to decompose the energy flows to obtain linear models [95]. However, this might lead to large errors because power flow equations for electricity and hydraulic networks are non-linear. 
Table 5 Segments and modelling approaches for components of future energy systems [40]

\begin{tabular}{lll}
\hline Field & Modelling approach & Components \\
\hline Physical world & Continuous models & $\begin{array}{l}\text { Energy infrastructure and its components: generation, } \\
\text { transport, distribution, consumption }\end{array}$ \\
Information Technology & Discrete models & Controllers, communication infrastructure, software \\
Roles and individual behaviour & Game theory models & Market players \\
Aggregated and stochastic elements & Statistical models & $\begin{array}{l}\text { Weather, macro-view on consumers, aggregated behaviour of } \\
\text { many individual elements }\end{array}$ \\
\hline
\end{tabular}

Including control systems in a MES model requires variable-structure, dynamic models [40]. Consumer behaviour and stochastic elements (Table 5) have rarely been included in energy system modelling to date. However, these factors are expected to be important in future applications despite adding many layers of complexity to the models. For example, in the UK, there are very few low carbon emission energy scenarios which also take into account social or political aspects [137]. The estimation of future energy demand and the required energy infrastructure can have significant influence on the future of energy supply [11]. In order to achieve a low-carbon emission future, energy demand must, in addition to energy supply, be addressed and managed [20, 138]. Furthermore, the public acceptance of renewable energy installations like rooftop solar panels in cities, on- and off-shore wind power plants, or new grid lines plays an important role for future energy systems. Overall, considering all four fields requires several different modelling methodologies, techniques and logics. This results in large stochastic hybrid models [40].

\section{Data}

Generally, there are two types of uncertainty: epistemic and aleatory [139]. An uncertainty is epistemic if the modeller thinks it can be reduced by better data and models, otherwise it is aleatory. There is no way to address epistemic uncertainties except for better models and data, but there are formal methods for dealing with aleatory uncertainties-an example is the Monte Carlo method. The Monte Carlo method, or similar approaches to determine uncertainty, examine the changes of a model's inputs and outputs by varying input data several times. The benefit of these methods is that they can be used in combination with existing deterministic models.

Stochastic models, for example, are designed to deal with uncertainties by handling a random input and producing a randomly distributed outcome. This means that distributions are fed into the model instead of deterministic parameters [11, 31]. Ideally, input data and parameters should be assigned with deviation ranges. However, the necessary input information might not always be of sufficient quality. Alternatively, it may be unavailable, or may only be available on an aggregated level because of data protection law limitations. If this is the case, then it must be adjusted or downscaled to the desired boundaries - for example from a national to a district level on a per-capita basis. Very often in these cases the uncertainty is difficult or impossible to determine. Unfortunately, the majority of studies do not describe the methods on how they dealt with the uncertainties related to their input data [31].

\section{Specific aspects}

The distributed nature and the necessary power-based perspective of RES mean that the modelling of time and space is crucial for accurate and robust results of MES models. Because it is very difficult to acquire sufficiently fine resolution data for RES, it is unlikely that traditional optimisation models (which use an energy based perspective) can fully represent the resolution challenges [11].

\section{Time and space}

Energy is not always supplied when and where it is required. This imbalance may be compensated for either spatially by the grid, or held by storage to be discharged at a later time. However, models with a high degree of spatial and temporal detail may require too much computational effort to be solved in an acceptable timeframe. Although a coarse resolution requires less computational effort, it can lead to inaccurate results. This is due its averaging character that may filter out the extreme points when designing the system [59]. Hayt et al. [58] determined in their work that models that do not consider the full variability of supply and demand can overestimate the share of demand met by renewable energies. There are three general approaches to address the variability of RES [11]: (1) capacity factors or load duration curves, (2) time slices of representative days or seasons and (3) real time series of RES production potential. Large-scale energy optimisation models like MARKAL/TIMES and MESSAGE use (1), but they may be adapted to be used with the time slices approach (2). For example Kannan et al. [61] presented such a model for the Swiss electricity system. Another example for the application of (2) is the LIMES model $[59,140]$. The application of real time series (3) can mainly be found in electricity system models [141, 142]. There are also hybrid models where long term energy system models are 
linked to short term operational power system models $[53,54,60]$.

The weather dependency of RES potentials requires highly resolved data in space. However, such spatially resolved data is generally only available in annual values (e.g. in [143] where the annual RES potentials on a district level for Austria are presented). A newer approach is the renewable.nija database which provides time and space resolved PV and wind potentials [131, 144]. The spatial distribution of demand was mainly addressed for the heating sector by two studies which investigated the heat demand in the UK [73, 74]. It was found that different levels of spatial resolution or aggregation also require a simplification of the energy networks. Network reduction is currently an important field for modellers of large-scale transmission power grids $[62,75,77,145,146]$. This is also an important consideration when modelling MES at a distribution level.

The cellular approach [147] is a method that supports network reduction. The studied area is divided into a number of cells, based on local conditions like consumers, producers and energy infrastructure. All individual entities of the same type within a cell are aggregated and represented by one single cell. Because the internal load flows of a cell are neglected, network reduction methods are necessary so that inter-cellular load flows are correctly represented. Because of the averaging effect of aggregation, the cellular approach allows the utilisation of standardised or synthetic load profiles if no high resolution data is available.

\section{Conclusions}

In this paper, we presented an overview of the current research and challenges of modelling grid-based MES. General and specific aspects of modelling grid-based energy carrier systems have been provided.

In order to provide a robust and efficient future energy supply, MES models should incorporate the interactions between different energy carriers, and the representation of load flows in grids. They should also enable the cost efficient integration of high shares of RES by using available synergies the different energy grids provide. The aspects which necessitate a power-based perspective in future planning models have been discussed. These aspects include the representation of modelling details, temporal and spatial resolutions, and network representations. Presented are three open source modelling frameworks that have been tested and used by the authors.

The challenges discussed show that there are still wide gaps and several opportunities for future research topics. From a technical perspective, the amalgamation of planning and operational models [11] is a major challenge. This is because it demands finer temporal and spatial resolutions and requires the implementation of a lot more technical details into the model. Moreover, the complexity of a model increases when accounting for interdisciplinary aspects such as the interdependency of the food and water sector [29], or human behaviour in an energy system. The most common model families, like simulation and optimisation, might not be sufficient for solving the resulting (usually non-linear) mathematical problem. Model coupling or new modelling approaches like agentbased-modelling might be necessary to obtain robust and relevant results.

\section{Endnotes}

${ }^{1}$ The flexibilities offered by one energy carrier that can be used by another energy carrier, e.g. the enormous storage capacity of the natural gas grid is used with power-to-gas plants [24].

${ }^{2}$ For example, World Energy Model (WEM), National Energy Modelling System - Residential Sector Demand Module (NEMS-RSDM)

${ }^{3}$ For example, MARKAL/TIMES, MESSAGE

${ }^{4}$ For example, Prospective Outlook on Long-term Energy System (POLES), Price-Induced Market Equilibrium System (PRIMES)

${ }^{5}$ https://www.neplan.ch

${ }^{6} \mathrm{https} / / / \mathrm{www}$. siemens.com/sincal

${ }^{7}$ https://www.digsilent.de/de/powerfactory.html

${ }^{8}$ Linepack is the quantity of gas contained in the pipe at a given time [98].

${ }^{9}$ www.github.com

${ }^{10} \mathrm{~A}$ commit is a contribution to a github project.

\section{Additional file}

Additional file 1: Additional file 1 includes the complete collection of open source energy modelling tools established from $[25,125,126]$. It includes: information regarding the host, the software license, the programming language, the mathematical model formulation, the availability of a documentation, the scope, the available energy sectors, possible time-resolutions and geo-resolutions, suitability to model multiple regions, and the possibility to model energy grids. (XLSX $20 \mathrm{~kb}$ )

\section{Abbreviations}

CHP: Combined heat and power; COP 21: 2015 United Nations Climate Change Conference; DP: Dynamic programming; EENS: Expected energy not served; LOEE: Loss of energy expectation; LOLE: Loss of load expectation LOLP: Loss of load probability; LP: Linear programming; MES: Multi-energy systems; MILP: Mixed-integer linear programming; NLMIP: Non-linear mixed-integer programming; RES: Renewable energy sources; VPP: Virtual power plant

\section{Acknowledgements \\ Not applicable.}

Funding

Not applicable. 


\section{Availability of data and materials}

All the data supporting the conclusions is included in the text. The source codes of the open source modelling frameworks are available on github; links are cited within the text.

\section{Authors' contributions}

The main work was conducted by LK: MES literature review and current challenges on energy systems modelling. GS carried out the analysis of open source energy modelling frameworks. TK initialised the work and revised and approved the final manuscript. All authors read and approved the final manuscript.

\section{Ethics approval and consent to participate}

Not applicable.

\section{Consent for publication}

Not applicable.

\section{Competing interests}

The authors declare that they have no competing interests.

\section{Publisher's Note}

Springer Nature remains neutral with regard to jurisdictional claims in published maps and institutional affiliations.

Received: 4 March 2018 Accepted: 17 October 2018

Published online: 13 November 2018

\section{References}

1. International Energy Agency (2017) Key world energy statistics: also available on smartphones and tablets. IEA Publications, Paris

2. Moriarty P, Honnery D (2012) What is the global potential for renewable energy? Renew Sust Energ Rev 16(1):244-252. https://doi.org/10.1016/j. rser.2011.07.15

3. Lewis NS, Nocera DG (2006) Powering the planet: Chemical challenges in solar energy utilization. Proc Natl Acad Sci U S A 103(43):15729-15735. https://doi.org/10.1073/pnas.060339510

4. CO2 Emissions From Fuel Combustion (2017) Overview (International Energy Agency, ed.). Organization for Economic Cooperation \& Development and Rowman \& Littlefield Publishers, Incorporated, Paris

5. United Nations Framework Convention of Climate Change (2015) United Nations Framework Convention on Climate Change: adoption of the Paris agreement (United Nations Framework Convention of Climate Change, ed.). United Nations, Paris. https://unfccc.int/sites/default/files/ english_paris_agreement.pdf. Accessed 27 Oct 2018

6. Helm D (2002) Energy policy: security of supply, sustainability and competition. Energy Policy 30(3):173-184

7. Strachan N, Fais B, Daly H (2016) Reinventing the energy modelling-policy interface. Nat Energy 1(3):16012. https://doi.org/10. 1038/nenergy.2016.1

8. Huntington H, Weyant JP, Sweeney JL (1982) Modeling for insights, not numbers: the experiences of the energy modeling forum. Omega 10(5):449-462. https://doi.org/10.1016/0305-0483(82)90002-0

9. Dantzig GB (1965) Linear programming and extensions. Second printing with corrections edn. Princeton University Press, Princeton

10. Zimmermann HJ (2005) Operations research: Methoden und Modelle; Für Wirtschaftsingenieure, Betriebswirte, Informatiker. 1. aufl edn. Mathematik für Wirtschaftswissenschaftler. Vieweg, Wiesbaden

11. Pfenninger S, Hawkes A, Keirstead J (2014) Energy systems modeling for twenty-first century energy challenges. Renew Sust Energ Rev 33:74-86. https://doi.org/10.1016/j.rser.2014.02.00

12. Pfenninger S, DeCarolis J, Hirth L, Quoilin S, Staffell I (2017) The importance of open data and software: Is energy research lagging behind? Energy Policy 101:211-215. https://doi.org/10.1016/j.enpol. 2016.11.04

13. Cao KK, Cebulla F, Gómez Vilchez JJ, Mousavi B, Prehofer S (2016) Raising awareness in model-based energy scenario studies-a transparency checklist. Energy Sustain Soc 6(1):519. https://doi.org/10.1186/s13705016-0090-z

14. Morrison R (2018) Energy system modeling: Public transparency, scientific reproducibility, and open development. Energy Strateg Rev 20:49-63. https://doi.org/10.1016/j.esr.2017.12.01
15. Collins S, Deane JP, Poncelet K, Panos E, Pietzcker RC, Delarue E, Ó Gallachóir BP (2017) Integrating short term variations of the power system into integrated energy system models: A methodological review. Renew Sust Energ Rev 76:839-856. https://doi.org/10.1016/j.rser.2017. 03.09

16. IEA-ETSAP (2008) MARKAL: MARket ALlocation. IEA-ETSAP. http://ieaetsap.org/index.php/etsap-tools/model-generators/markal. Accessed 04 Dec 2017

17. Agnew M, Schrattenholzer L, Voss A (2017) A model for energy supply systems alternatives and their general environmental impact. IIASA, Laxenburg, Austria. http://pure.iiasa.ac.at/1177/. Accessed 07 Dec 2017

18. Messner S (1984) User's guide for the matrix generator of message II. Parts I and II: Model Description and Implementation Guide, and Appendices. IIASA, Laxenburg, Austria. http://pure.iiasa.ac.at/2447/. Accessed 07 Dec 2017

19. Mancarella P, Andersson G, Pecas-Lopes JA, Bell KRW (2016) Modelling of integrated multi-energy systems: drivers, requirements, and opportunities. In: 2016 Power Systems Computation Conference (PSCC). IEEE. pp 1-22. https://doi.org/10.1109/PSCC.2016.754103

20. Brauner G (2016) Energiesysteme: Regenerativ und Dezentral. Springer Fachmedien Wiesbaden, Wiesbaden. https://doi.org/10.1007/978-3658-12755-8

21. Ruiz-Romero S, Colmenar-Santos A, Mur-Pérez F, López-Rey Á (2014) Integration of distributed generation in the power distribution network: the need for smart grid control systems, communication and equipment for a smart city - Use cases. Renew Sust Energ Rev 38:223-234. https://doi.org/10.1016/j.rser.2014.05.08

22. Heimberger M, Kaufmann T, Maier C, Nemec-Begluk S, Winter A, Gawlik W (2017) Energieträgerübergreifende Planung und Analyse von Energiesystemen. Elektrotechnik Informationstechnik 134(3):229-237. https://doi.org/10.1007/s00502-017-0504-

23. Heinrichs HU (2013) Analyse der Langfristigen Auswirkungen Von Elektromobilität Auf Das Deutsche Energiesystem Im Europäischen Energieverbund. In: Produktion und Energie / Karlsruher Institut für Technologie, Institut für Industriebetriebslehre und industrielle Produktion u. Deutsch-Französisches Institut für Umweltforschung, vol. 5, Print on demand edn. KIT Scientific Publishing, Karlsruhe

24. O'Malley M, Kroposki B, Hannegan B, Madsen H, Andersson M, D'haeseleer W, McGranaghan MF, Dent C, Strbac G, Baskaran S, Rinker M (2016) Energy Systems Integration. Defining and Describing the Value Proposition. https://doi.org/10.2172/125767

25. Energypedia (2017) openmod intiative. https://wiki.openmod-initiative. org/wiki/Open_Models. Accessed 17 Nov 2017

26. Pfenninger S, Hirth L, Schlecht I, Schmid E, Wiese F, Brown T, Davis C, Gidden M, Heinrichs H, Heuberger C, Hilpert S, Krien U, Matke C, Nebel A, Morrison R, Müller B, Pleßmann G, Reeg M, Richstein JC, Shivakumar A, Staffell I, Tröndle T, Wingenbach C (2018) Opening the black box of energy modelling: Strategies and lessons learned. Eng Strateg Rev 19:63-71. https://doi.org/10.1016/j.esr.2017.12.00

27. (2012) Global Energy Assessment (GEA): Toward a Sustainable Future. 1. publ edn(Johansson TB, ed.). Cambridge Univ. Press, Cambridge u.a.

28. Mancarella P (2014) MES (multi-energy systems): An overview of concepts and evaluation models. Energy 65:1-17. https://doi.org/10. 1016/j.energy.2013.10.04

29. Wiese F, Hilpert S, Kaldemeyer C, Pleßmann G (2018) A qualitative evaluation approach for energy system modelling frameworks. Energy Sustain Soc 8(1):211. https://doi.org/10.1186/s13705-018-0154-3

30. Mohammadi M, Noorollahi Y, Mohammadi-ivatloo B, Yousefi H (2017) Energy hub: from a model to a concept - a review. Renew Sust Energ Rev 80:1512-1527. https://doi.org/10.1016/j.rser.2017.07.03

31. Keirstead J, Jennings M, Sivakumar A (2012) A review of urban energy system models: approaches, challenges and opportunities. Renew Sust Energ Rev 16(6):3847-3866. https://doi.org/10.1016/j.rser.2012.02.04

32. van Beuzekom I, Gibescu M, Slootweg JG (2015) A review of multi-energy system planning and optimization tools for sustainable urban development. In: 2015 IEEE Eindhoven PowerTech. pp 1-7. https://doi.org/10.1109/PTC.2015.723236. http://ieeexplore.ieee.org/ stamp/stamp.jsp?arnumber $=7232360$

33. Hall LMH, Buckley AR (2016) A review of energy systems models in the UK: prevalent usage and categorisation. Appl Energy 169:607-628. https://doi.org/10.1016/j.apenergy.2016.02.04 
34. Syranidis K, Robinius M, Stolten D (2018) Control techniques and the modeling of electrical power flow across transmission networks. Renew Sust Energ Rev 82:3452-3467. https://doi.org/10.1016/j.rser.2017.10.11

35. Box GEP, Draper NR (1987) Empirical model-building and response surfaces. Wiley Ser Probab Math Stat. Wiley, Oxford

36. Herbst A, Toro F, Reitze F, Jochem E (2012) Introduction to energy systems modelling. Swiss J Econ Stat 148(2):111-135. https://doi.org/10. 1007/BF0339936

37. Connolly D, Lund $H$, Mathiesen BV, Leahy M (2010) A review of computer tools for analysing the integration of renewable energy into various energy systems. Appl Energy 87(4):1059-1082. https://doi.org/ 10.1016/j.apenergy.2009.09.02

38. Thiem S (2017) Multi-modal on-site energy systems: development and application of a superstructure-based optimization method for energy system design under consideration of part-load efficiencies. PhD, Technische Universität München, München

39. Palensky P, Widl E, Stifter M, Elsheikh A (2013) Modeling intelligent energy systems: co-simulation platform for validating flexible-demand EV charging management. IEEE Trans Smart Grid 4(4):1939-1947. https://doi.org/10.1109/TSG.2013.225805

40. Palensky P, Widl E, Elsheikh A (2014) Simulating cyber-physical energy systems: challenges, tools and methods. IEEE Trans Syst Man Cybern Syst 44(3):318-326. https://doi.org/10.1109/TSMCC.2013.226573

41. van Beeck NMJP (1999) Classification of energy models. FEW Research Memorandum. Operations research, Tilburg

42. Ommen T, Markussen WB, Elmegaard B (2014) Comparison of linear, mixed integer and non-linear programming methods in energy system dispatch modelling. Energy 74:109-118. https://doi.org/10.1016/j. energy.2014.04.02

43. (2016) The physics of stocks and flows of energy systems. SpringerBriefs in Complexity(Qudrat-Ullah H, ed.). Springer International Publishing, Cham. https://doi.org/10.1007/978-3-319-24829-

44. Wagner PH, Wittmann M (2014) Influence of different operation strategies on transient solar thermal power plant simulation models with molten salt as heat transfer fluid. Energy Procedia 49:1652-1663. https://doi.org/10.1016/j.egypro.2014.03.17

45. Steen D, Stadler M, Cardoso G, Groissböck M, DeForest N, Marnay C (2015) Modeling of thermal storage systems in MILP distributed energy resource models. Appl Energy 137:782-792. https://doi.org/10.1016/j. apenergy.2014.07.03

46. Gönen T, Foote BL (1982) Mathematical dynamic optimization model for electrical distribution system planning. Int J Electr Power Energy Syst 4(2):129-136. https://doi.org/10.1016/0142-0615(82)90039-4

47. Tashiro T, Tamura K, Yasuda K (2011) Modeling and optimal operation of distributed energy systems via dynamic programming. In: 2011 IEEE International Conference on Systems, Man, and Cybernetics. IEEE. pp 808-813. https://doi.org/10.1109/ICSMC.2011.608375

48. Bell KRW, Tleis AND (2010) Test system requirements for modelling future power systems. In: IEEE PES General Meeting. IEEE. pp 1-8. https:// doi.org/10.1109/PES.2010.558980

49. Aien M, Hajebrahimi A, Fotuhi-Firuzabad M (2016) A comprehensive review on uncertainty modeling techniques in power system studies. Renew Sust Energ Rev 57:1077-1089. https://doi.org/10.1016/j.rser.2015. 12.07

50. Aien M, Rashidinejad M, Fotuhi-Firuzabad M (2014) On possibilistic and probabilistic uncertainty assessment of power flow problem: A review and a new approach. Renew Sust Energ Rev 37:883-895. https://doi.org/ 10.1016/j.rser.2014.05.06

51. Zadeh LA (1999) Fuzzy sets as a basis for a theory of possibility. Fuzzy Sets Syst 100:9-34. https://doi.org/10.1016/S0165-0114(99)80004-9

52. Cai YP, Huang GH, Yang ZF, Tan Q (2009) Identification of optimal strategies for energy management systems planning under multiple uncertainties. Appl Energy 86(4):480-495. https://doi.org/10.1016/j. apenergy.2008.09.02

53. Poncelet K, Delarue E, Six D, Duerinck J, D'haeseleer W (2016) Impact of the level of temporal and operational detail in energy-system planning models. Appl Energy 162:631-643. https://doi.org/10.1016/j.apenergy. 2015.10.10

54. Deane JP, Chiodi A, Gargiulo M, Ó Gallachóir BP (2012) Soft-linking of a power systems model to an energy systems model. Energy 42(1):303-312. https://doi.org/10.1016/j.energy.2012.03.05
55. Welsch M, Mentis D, Howells M (2014) Long-term energy systems planning. In: Jones LE (ed). Renewable Energy Integration. Elsevier. pp 215-225. https://doi.org/10.1016/B978-0-12-407910-6.00017-X

56. van Stiphout A, de Vos K, Deconinck G (2017) The impact of operating reserves on investment planning of renewable power systems. IEEE Trans Power Syst 32(1):378-388. https://doi.org/10.1109/TPWRS.2016.256505

57. Palmintier B (2014) Flexibility in generation planning: identifying key operating constraints. In: 2014 Power Systems Computation Conference. IEEE. pp 1-7. https://doi.org/10.1109/PSCC.2014.703832

58. Haydt G, Leal V, Pina A, Silva CA (2011) The relevance of the energy resource dynamics in the $\mathrm{mid} /$ long-term energy planning models. Renew Energy 36(11):3068-3074. https://doi.org/10.1016/j.renene.2011. 03.02

59. Ludig S, Haller M, Schmid E, Bauer N (2011) Fluctuating renewables in a long-term climate change mitigation strategy. Energy 36(11):6674-6685 https://doi.org/10.1016/j.energy.2011.08.02

60. Pina A, Silva CA, Ferrão P (2013) High-resolution modeling framework for planning electricity systems with high penetration of renewables. Appl Energy 112:215-223. https://doi.org/10.1016/j.apenergy.2013.05.07

61. Kannan R, Turton H (2013) A long-term electricity dispatch model with the TIMES framework. Environ Model Assess 18(3):325-343. https://doi. org/10.1007/s10666-012-9346-

62. Koltsaklis NE, Dagoumas AS, Kopanos GM, Pistikopoulos EN, Georgiadis MC (2014) A spatial multi-period long-term energy planning model: a case study of the Greek power system. Appl Energy 115:456-482. https://doi. org/10.1016/j.apenergy.2013.10.04

63. Biberacher M, Gadocha S, Vliet O (2013) Envirolnfo 2013 - Environmenta Informatics and Renewable Energies. In: Page B, Fleischer AG, Göbel J, Wohlgemuth $V$ (eds). Shaker, Aachen

64. Dyckhoff H, Spengler TS (2007) Produktionswirtschaft: Eine Einführung Für Wirtschaftsingenieure; Mit 10 Tabellen. 2, verb. aufl. edn. Springer-Lehrbuch. Springer, Berlin and Heidelberg. https://doi.org/10. 1007/978-3-540-72218-. http://site.ebrary.com/lib/alltitles/docDetail. action?doclD=10187412

65. Reynolds J, Ahmad MW, Rezgui Y (2018) Holistic modelling techniques for the operational optimisation of multi-vector energy systems. Energy Build 169:397-416. https://doi.org/10.1016/j.enbuild.2018.03.06

66. Kerdoncuff $P$ (2008) Modellierung und Bewertung Von Prozessketten zur Herstellung Von Biokraftstoffen der Zweiten Generation: Zugl.: Karlsruhe, Univ., Diss. Univ.-Verl. Karlsruhe, Karlsruhe

67. Li X, Wen J (2014) Review of building energy modeling for control and operation. Renew Sust Energ Rev 37:517-537. https://doi.org/10.1016/j. rser.2014.05.05

68. Good N, Zhang L, Navarro-Espinosa A, Mancarella P (2015) High resolution modelling of multi-energy domestic demand profiles. Appl Energy 137:193-210. https://doi.org/10.1016/j.apenergy.2014.10.02

69. Corrado V, Fabrizio E, Filippi M (2007) Modelling and optimization of multi-energy source building systems in the design concept phase. In: Proceedings of Clima 2007

70. van Beuzekom I, Gibescu M, Pinson P, Slootweg JG (2017) Optimal planning of integrated multi-energy systems. In: 2017 IEEE Manchester PowerTech. pp 1-6. https://doi.org/10.1109/PTC.2017.798088. http:// ieeexplore.ieee.org/stamp/stamp.jsp?arnumber $=7980886$

71. Lund H, Mathiesen BV (2009) Energy system analysis of $100 \%$ renewable energy systems - the case of Denmark in years 2030 and 2050. Energy 34(5):524-531. https://doi.org/10.1016/j.energy.2008.04.00

72. Pillai JR, Heussen K, Østergaard PA (2011) Comparative analysis of hourly and dynamic power balancing models for validating future energy scenarios. Energy 36(5):3233-3243. https://doi.org/10.1016/j.energy. 2011.03 .01

73. Li F (2013) Spatially explicit techno-economic optimisation modelling of UK heating futures

74. Munuera L (2014) Technology_rich economic modelling and analysis of residential heating systems for low carbon energy policy support

75. Di Shi, Tylavsky DJ (2015) A Novel Bus-Aggregation-Based Structure-Preserving Power System Equivalent. IEEE Trans Power Syst 30(4):1977-1986. https://doi.org/10.1109/TPWRS.2014.235944

76. Horsch J, Brown T (2017) The role of spatial scale in joint optimisations of generation and transmission for European highly renewable scenarios. In: 2017 14th International Conference on the European Energy Market (EEM). IEEE. pp 1-7. https://doi.org/10.1109/EEM.2017.798202 
77. Corcoran BA, Jenkins N, Jacobson MZ (2012) Effects of aggregating electric load in the United States. Energy Pol 46:399-416. https://doi. org/10.1016/j.enpol.2012.03.07

78. Hawkes AD, Leach MA (2005) Impacts of temporal precision in optimisation modelling of micro-Combined Heat and Power. Energy 30(10):1759-1779. https://doi.org/10.1016/j.energy.2004.11.01

79. Martens A (1998) The energetic feasibility of CHP compared to the separate production of heat and power. Appl Therm Eng 18(11):935-946. https://doi.org/10.1016/S1359-4311(98)00026-X

80. Wall G (1977) Exergy: A useful concept within resource accounting

81. Billinton R, Allan RN (1996) Reliability evaluation of power systems. 2nd ed. Plenum Press, New York

82. Geidl M, Koeppel G, Perrod PF, Klockl B, Andersson G, Frohlich K (2007) Energy hubs for the future. IEEE Power Energy Mag 5(1):24-30. https:// doi.org/10.1109/MPAE.2007.26485

83. Schavemaker $P$, van der Sluis $L$ (2009) Electrical power system essentials. Reprint. with corr edn. Wiley, Chichester

84. Medjroubi W, Müller UP, Scharf M, Matke C, Kleinhans D (2017) Open data in power grid modelling: new approaches towards transparent grid models. Energy Rep 3:14-21. https://doi.org/10.1016/j.egyr.2016.12.00

85. Kile H, Uhlen K, Warland L, Kjolle G (2014) A comparison of AC and DC power flow models for contingency and reliability analysis. In: 2014 Power Systems Computation Conference. IEEE. pp 1-7. https://doi.org/ 10.1109/PSCC.2014.703845

86. Gunkel D, Most D (2014) The German transmission grid expansion in long-term perspective - What is the impact of renewable integration? In: 11 th International Conference on the European Energy Market (EEM14). IEEE. pp 1-6. https://doi.org/10.1109/EEM.2014.686121

87. Mobius T, Gunkel D (2014) The optimal placing of energy storages in Germany in 2020 - an implementation of a DC-load flow model. In: 11th International Conference on the European Energy Market (EEM14). IEEE. pp 1-5. https://doi.org/10.1109/EEM.2014.686124

88. Sahin C (2018) Consideration of network constraints in the Turkish day ahead electricity market. Int J Electr Power Energy Syst 102:245-253. https://doi.org/10.1016/j.ijepes.2018.04.02

89. Eldridge $B$, O'Neill R, Castillo A (2018) An improved method for the DCOPF with losses. IEEE Trans Power Syst 33(4):3779-3788. https://doi. org/10.1109/TPWRS.2017.277608

90. Murari K, Padhy NP (2018) A network-topology based approach for the load flow solution of AC-DC distribution system with distributed generations. IEEE Trans Ind Inf:1. https://doi.org/10.1109/TII.2018.285271

91. Fathtabar H, Barforoushi T, Shahabi M (2018) Dynamic long-term expansion planning of generation resources and electric transmission network in multi-carrier energy systems. Int J Electr Power Energy Syst 102:97-109. https://doi.org/10.1016/j.ijepes.2018.04.01

92. Frank S, Steponavice I, Rebennack S (2012) Optimal power flow: a bibliographic survey I. Energy Syst 3(3):221-258. https://doi.org/10. 1007/s12667-012-0056-y

93. Geidl M, Andersson G (2007) Optimal power flow of multiple energy carriers. IEEE Trans Power Syst 22(1):145-155. https://doi.org/10.1109/ TPWRS.2006.88898

94. Xu X, Li K, Liu Y, Jia H (2016) Integrated optimal power flow for distribution networks in local and urban scales. In: 2016 UKACC 11th International Conference on Control (CONTROL). IEEE. pp 1-6. https:// doi.org/10.1109/CONTROL.2016.773752

95. Almassalkhi M, Hiskens I (2011) Optimization framework for the Analysis of large-scale networks. In: Proceedings of 17th Power Systems Computation Conference. http://ieeexplore.ieee.org/stamp/stamp.jsp? arnumber $=6161484$

96. Liu X, Yuan CL, Liu XY, Luo F-h, Feng Q, Xu J, Chen GH, Zhou CR (2016) Microstructures, electrical behavior and energy-storage properties of $\mathrm{Ba} 0.06 \mathrm{Na} 0.47 \mathrm{Bi0}$.47TiO3-Ln1/3NbO3 ( $\mathrm{Ln}=\mathrm{La}$, Nd, Sm) ceramics. Mater Chem Phys 181:444-451. https://doi.org/10.1016/j.matchemphys.2016. 06.08

97. Liu C, Shahidehpour M, Wang J (2011) Coordinated scheduling of electricity and natural gas infrastructures with a transient model for natural gas flow. Chaos (Woodbury, N.Y.) 21(2):025102. https://doi.org/ 10.1063/1.360076

98. Clegg S, Mancarella P (2016) Integrated electrical and gas network flexibility assessment in low-carbon multi-energy systems. In: 2016 IEEE Power and Energy Society General Meeting (PESGM). IEEE. p 1. https:// doi.org/10.1109/PESGM.2016.774150
99. Li Z, Wu W, Wang J, Zhang B, Zheng T (2016) Transmission-constrained unit commitment considering combined electricity and district heating networks. IEEE Trans Sust Energy 7(2):480-492. https://doi.org/10.1109/ TSTE.2015.250057

100. Geidl M (2007) Integrated modeling and optimization of multi-carrier energy systems. Dissertation. ETH Zürich, Zürich

101. Morvaj B, Evins R, Carmeliet J (2017) Comparison of individual and microgrid approaches for a distributed multi energy system with different renewable shares in the grid electricity supply. Energy Procedia 122:349-354. https://doi.org/10.1016/j.egypro.2017.07.33

102. Asmus $P$ (2010) Microgrids, virtual power plants and our distributed energy future. Electr J 23(10):72-82. https://doi.org/10.1016/j.tej.2010.11. 00

103. Heussen K, Koch S, Ulbig A, Andersson G (2010) Energy storage in power system operation: the power nodes modeling framework. In: 2010 IEEE PES Innovative Smart Grid Technologies Conference Europe (ISGT Europe). pp 1-8. https://doi.org/10.1109/ISGTEUROPE.2010.563886. http://ieeexplore.ieee.org/stamp/stamp.jsp?arnumber=5638865

104. Geidl M, Andersson G (2005) Operational and topological optimization of multi-carrier energy systems. In: 2005 International Conference on Future Power Systems. pp 6-6. https://doi.org/10.1109/FPS.2005.20419. http://ieeexplore.ieee.org/stamp/stamp.jsp?arnumber=1600472

105. Andersson G, Fröhlich K, Krause T (2011) Vision of future energy networks (VoFEN): Schlussbericht: Phase 2, Zürich

106. Geidl M, Andersson G (2005) Optimal power dispatch and conversion in systems with multiple energy carriers. In: Proceedings of the 15th Power System Computation Conference (PSSC)

107. Koeppel G (2007) Reliability considerations of future energy systems: multi-carrier systems and the effect of energy storage. Dissertation

108. Krause T, Kienzle F, Art S, Andersson G (2010) Maximizing exergy efficiency in multi-carrier energy systems. In: Energy Society General Meeting. pp 1-8. https://doi.org/10.1109/PES.2010.558999

109. Lasseter RH (2011) Smart distribution: coupled microgrids. Proc IEEE 99(6):1074-1082. https://doi.org/10.1109/JPROC.2011.211463

110. Piacentino A, Barbaro C, Cardona F, Gallea R, Cardona E (2013) A comprehensive tool for efficient design and operation of polygeneration-based energy micro-grids serving a cluster of buildings. Part I: Description of the method. Appl Energy 111:1204-1221. https:// doi.org/10.1016/j.apenergy.2012.11.07

111. Piacentino A, Barbaro C (2013) A comprehensive tool for efficient design and operation of polygeneration-based energy micro-grids serving a cluster of buildings. Part II: Analysis of the applicative potential. Appl Energy 111:1222-1238. https://doi.org/10.1016/j.apenergy.2012.11.07

112. Bracco S, Delfino F, Pampararo F, Robba M, Rossi M (2014) A mathematical model for the optimal operation of the University of Genoa Smart Polygeneration Microgrid: evaluation of technical, economic and environmental performance indicators. Energy 64:912-922. https://doi.org/10.1016/j.energy.2013.10.03

113. Corera J (2009) FENIX: Flexible electricity networks to integrate the expected energy evolution: results. http://www.fenix-project.org/. Accessed 22 Nov 2017

114. Ropenus S, Skytte K (2005) Regulatory review and barriers for the electricity supply system for distributed generation in EU-15. In: 2005 International Conference on Future Power Systems. pp 6-6. https://doi. org/10.1109/FPS.2005.20426. http://ieeexplore.ieee.org/stamp/stamp. jsp?arnumber $=1600534$

115. eex group (2018) EEX Exchange Rules, Leipzig. https://www.eex.com/ blob/80166/898f6187342da3502e48b4516b96a42c/eex-exchangerules-en-data.pdf. Accessed 24 May 2018

116. Austrian Power Grid (2017) Conditions for participation in tenders for control energy. https://www.apg.at/en/market/balancing/conditionsfor-participation. Accessed 22 Nov 2017

117. German transmission system operators (2017) regelleistung.net: Internetplattform zur Vergabe von Regelleistung. www.regelleistung. net. Accessed 22 Nov 2017

118. Wille-Haussmann B, Erge T, Wittwer C (2010) Decentralised optimisation of cogeneration in virtual power plants. Solar Energy 84(4):604-611. https://doi.org/10.1016/j.solener.2009.10.00

119. Wang D, Parkinson S, Miao W, Jia H, Crawford C, Djilali N (2013) Hierarchical market integration of responsive loads as spinning reserve. Appl Energy 104:229-238. https://doi.org/10.1016/j.apenergy.2012.10.05 
120. Kusch W, Schmidla T, Stadler I (2012) Consequences for district heating and natural gas grids when aiming towards 100\% electricity supply with renewables. Energy 48(1):153-159. https://doi.org/10.1016/j.energy. 2012.06.05

121. Lind M (2011) An introduction to multilevel flow modeling. Int J Nucl Saf Simul 2(1):22-32

122. Heussen K, Koch S, Ulbig A, Andersson G (2012) Unified system-level modeling of intermittent renewable energy sources and energy storage for power system operation. IEEE Syst J 6(1):140-151. https://doi.org/10. 1109/JSYST.2011.216302

123. Heussen K (2011) Control architecture modeling for future power systems

124. Bakken BH, Holen AT (2004) Energy service systems: integrated planning case studies. In: IEEE Power Engineering Society General Meeting, 2004. pp 2068-2073. https://doi.org/10.1109/PES.2004.137324. http:// ieeexplore.ieee.org/stamp/stamp.jsp?arnumber=1373245

125. EnergyPLAN (2017) Other tools: links to energy system analysis models. http://www.energyplan.eu/othertools/. Accessed 24 Nov 2017

126. Wikipedia (2017) Open energy system models. https://en.wikipedia.org/ wiki/Open_energy_system_models. Accessed 23 Nov 2017

127. Wiese F, Bramstoft R, Koduvere H, Pizarro Alonso A, Balyk O, Kirkerud JG, Tveten ÅG, Bolkesjø TF, Münster M, Ravn H (2018) Balmorel open source energy system model. Energy Strat Rev 20:26-34. https://doi.org/10. 1016/j.esr.2018.01.00

128. Atabay D (2017) An open-source model for optimal design and operation of industrial energy systems. Energy 121:803-821. https://doi. org/10.1016/j.energy.2017.01.03

129. Brown T, Hörsch J, Schlachtberger D (2018) PyPSA: Python for power system analysis. J Open Res Softw 6(3):12. https://doi.org/10.5334/jors.18

130. Andresen L, Dubucq P, Peniche Garcia R, Ackermann G, Kather A, Schmitz G (2015) Status of the transient library: transient simulation of coupled energy networks with high share of renewable energy. In: Linköping Electronic Conference Proceedings. Linköping University Electronic Press. pp 695-705. https://doi.org/10.3384/ecp1511869

131. Pfenninger S (2017) Dealing with multiple decades of hourly wind and PV time series in energy models: a comparison of methods to reduce time resolution and the planning implications of inter-annual variability. Appl Energy 197:1-13. https://doi.org/10.1016/j.apenergy.2017.03.05

132. oemof Developer Group (2017) Open Energy Modelling Framework (Oemof) - A Modular Open Source Framework To Model Energy Supply Systems. Version V0.1.4. Zenodo. https://doi.org/10.5281/zenodo.43867

133. Dorfner J, Dorfner M, Schönleber K, Zipperle T, Herzog S, Siala K, Akca O (2017) Tum-Ens/Urbs: V0.7.2. Zenodo. https://doi.org/10.5281/zenodo. 59420

134. Hilpert S, Günther S, Kaldemeyer C, Krien U, Plessmann G, Wiese F, Wingenbach C (2017) Addressing energy system modelling challenges: the contribution of the open energy modelling framework (oemof). https://doi.org/10.20944/preprints201702.0055.v

135. Fisk DJ, Kerhervé J (2006) Complexity as a cause of unsustainability. Ecol Complex 3(4):336-343. https://doi.org/10.1016/j.ecocom.2007.02.00

136. Ulanowicz RE, Goerner SJ, Lietaer B, Gomez R (2009) Quantifying sustainability: resilience, efficiency and the return of information theory. Ecol Complex 6(1):27-36. https://doi.org/10.1016/j.ecocom.2008.10.00

137. Hughes N, Strachan N (2010) Methodological review of UK and international low carbon scenarios. Energy Pol 38(10):6056-6065. https://doi.org/10.1016/j.enpol.2010.05.06

138. Strbac G (2008) Demand side management: Benefits and challenges. Energy Pol 36(12):4419-4426. https://doi.org/10.1016/j.enpol.2008.09.03

139. Kiureghian AD, Ditlevsen $O$ (2009) Aleatory or epistemic? Does it matter? Struct Saf 31(2):105-112. https://doi.org/10.1016/j.strusafe.2008.06.02

140. Haller M, Ludig S, Bauer N (2012) Decarbonization scenarios for the EU and MENA power system: Considering spatial distribution and short term dynamics of renewable generation. Energy Pol 47:282-290. https:// doi.org/10.1016/j.enpol.2012.04.06

141. Fripp M (2012) Switch: A planning tool for power systems with large shares of intermittent renewable energy. Environ Sci Technol 46(11):6371-6378. https://doi.org/10.1021/es204645

142. Pfluger $B$, Wietschel $M(2012)$ Impact of renewable energies on conventional power generation technologies and infrastructures from a long-term least-cost perspective. In: 2012 9th International Conference on the European Energy Market. IEEE. pp 1-10. https://doi.org/10.1109/ EEM.2012.625476

143. Stanzer G, Novak S, Dumke H, Plha S, Schaffer H, Breinesberger J, Kirtz M, Biermayer P, Spanring C REGIO Energy: Regionale Szenarien erneuerbarer Energiepotenziale in den Jahren 2012/2020, Wien and St. Pölten. http://regioenergy.oir.at/sites/regioenergy.oir.at/files/uploads/ pdf/REGIO-Energy_Endbericht_201013_korr_Strom_Waerme.pdf. Accessed 12 Jan 2018

144. Staffell I, Pfenninger S (2016) Using bias-corrected reanalysis to simulate current and future wind power output. Energy 114:1224-1239. https:// doi.org/10.1016/j.energy.2016.08.06

145. Shawhan D, Taber J, Zimmerman R, Yan J, Marquet C, Schulze W, Schuler R, Thomas R, Tylavsky D, Shi D, Li N, Jewell W, Hardy T, Hu Z (2015) A detailed power system planning model: estimating the long-run impact of carbon-reducing policies. In: 2015 48th Hawaii International Conference on System Sciences. IEEE. pp 2497-2506. https://doi.org/10. 1109/HICSS.2015.30

146. Schlachtberger DP, Brown T, Schramm S, Greiner M (2017) The benefits of cooperation in a highly renewable European electricity network. Energy 134:469-481. https://doi.org/10.1016/j.energy.2017.06.00

147. Böckl B, Kriechbaum L, Kienberger T (2016) Analysemethode für kommunale Energiesysteme unter Anwendung des zellularen Ansatzes. In: Institut für Elektrizitätswirtschaft und Energieinnovation (ed.) 14. Symposium Energieinnovation. TU Graz, Graz

\section{Ready to submit your research? Choose BMC and benefit from}

- fast, convenient online submission

- thorough peer review by experienced researchers in your field

- rapid publication on acceptance

- support for research data, including large and complex data types

- gold Open Access which fosters wider collaboration and increased citations

- maximum visibility for your research: over $100 \mathrm{M}$ website views per year

At BMC, research is always in progress.

Learn more biomedcentral.com/submissions 